\title{
O PRINCÍPIO DA LEGALIDADE TRIBUTÁRIA EM SUA APLICABILIDADE PROCESSUAL AOS IMPOSTOS FEDERAIS
}

\section{ARTIGO ORIGINAL}

CARDOSO, Lucas Giribone ${ }^{1}$

CARDOSO, Lucas Giribone. O princípio da legalidade tributária em sua aplicabilidade processual aos impostos federais. Revista Científica Multidisciplinar Núcleo do Conhecimento. Ano 05, Ed. 12, Vol. 18, pp. 51-66. Dezembro de 2020. ISSN: 2448-0959,

Link de acesso: https://www.nucleodoconhecimento.com.br/lei/legalidade-tributaria

\section{RESUMO}

O princípio da legalidade previsto na Constituição Federal de 1988 é um alicerce, do qual sustenta o ordenamento jurídico tributário brasileiro, limitando e regulando as ações do estado em frente a arrecadação de tributos. A União Federal é a pessoa jurídica de Direito Público, da qual obtém grande número de arrecadação de impostos, da qual deverá observar os limites impostos pela lei, considerando os requisitos de imunidade e isenção. Para a realização desta pesquisa, será adotado como metodologia a análise bibliográfica de outros artigos científico, bem como a doutrina sobre o tema, levando em consideração os entendimentos jurisprudenciais adotados pelos tribunais superiores. Com isso, espere-se obter resultados que comprovem a relevância desta temática ao universo jurídico tributário, a fim de inspirar novas pesquisas sobre este mesmo assunto.

\footnotetext{
${ }^{1}$ Advogado, Bacharel em Direito e Especialista em Direito Tributário pela Universidade Presbiteriana Mackenzie, mestrando em Direito, no núcleo de pesquisa em Direito Constitucional e Processual Tributário da Pontifícia Universidade Católica de São Paulo (PUC-SP).
} 
Palavras-Chave: Legalidade, Constituição Federal, análise, limites, cobrança tributária.

\section{INTRODUÇÃO}

A Constituição da República Federativa do Brasil de 1988 é o documento fundamental do ordenamento jurídico pátrio, do qual traz as principais bases do Direito Nacional, inclusive quanto a matéria tributária. Os artigos 145 a 162 desta Carta Magna trazem as normas do sistema tributário nacional, inclusive quanto aos seus princípios, como no caso o princípio da legalidade, do qual tem sua previsão primária no artigo $5^{\circ}$, inciso Il da Constituição Federal de 1988. Para que seja instituído o tributo, deverá haver lei anterior, que o pré-estabeleça, pois caso contrário, tornar-Ihe-ia sua exigibilidade nula. A União Federal é um dos entes públicos, dos quais possui capacidade tributária ativa e competência legislativas para instituir seus impostos, como assim prevê o artigo 153 desta Constituição, mas poderá criar impostos se assim houver possibilidade legal.

O processo de cobranças dos impostos federais poderá ocorrer tanto na esfera administrativa, por meio de seus órgãos como a Receita Federal do Brasil, através da lei de processo administrativo federal (lei 9.784/99), como também na esfera da justiça federal junto aos Tribunais Regionais Federal e cortes superiores, seguindo a previsão do Código de Processo Civil de 2015. Em ambos os casos, o princípio da legalidade sempre será levado em consideração, pois seu descumprimento e inobservância por parte da Administração Pública leva a nulidade do ato administrativo, com base no artigo 37, caput da Constituição Federal de 1988. Outra restrição por parte da lei, é em relação dos impostos previstos na constituição, dos quais necessitam de lei complementar prévia, para serem instituídos.

A relação entre a União Federal e o contribuinte dentro da relação processual será analisada, sob a ótica do princípio da legalidade, levando em consideração os entendimentos do Supremo Tribunal Federal, do Superior Tribunal de Justiça e dos tribunais federais, a fim de ser entendido seu contexto de maneira mais clara e completa. Esta relação tributária muitas das vezes é levada ao litígio, cabendo com isso a presença das instâncias judiciais, a fim de analisar o mérito quanto a legalidade 
ou a ilegalidade de um imposto federal, como, por exemplo, o imposto de renda retido na fonte. O planejamento tributário também pode entrar neste contexto, visto que as brechas da lei dão ao contribuinte a possibilidade de procurar realizar sua elisão fiscal, o que muitas das vezes é contrastado pela Fazenda Pública, da qual tem o interesse na arrecadação, levando em consideração os limites da lei.

\section{PRINCÍPIO DA LEGALIDADE NA CONSTITUIÇÃO FEDERAL DE 1988 E NO CÓDIGO TRIBUTÁRIO NACIONAL}

A origem do princípio da legalidade é muito antiga, sendo esta herdada pela Constituição Federal de 1988, a fim de regulamentar e limitar as atuações do poder do estado inclusive quanto ao poder de tributar, assim estabelecendo em quais situações em que o estado irá poder tributar, ou seja, estabelecer o tributo quando há a prática do fato gerador. Neste sentido, o autor Ricardo Lodi Ribeiro, em sua obra "Legalidade Tributária, tipicidade aberta, conceitos indeterminados e cláusulas gerais tributárias", assim dispõe:

É a definição da hipótese de incidência pelo legislador que vai definir a maior ou menor abertura do tipo. No entanto, sempre restará ao intérprete um espaço de adequação da norma à realidade (RIBEIRO, 2019, p. 320).

A União Federal tem uma ampla gama de tributação de impostos, podendo esta cobrar, por exemplo, o Imposto de Renda da Pessoa Física ou Jurídica, Imposto sobre a Propriedade de Território Rural, Impostos de Importação e entre outros, gerando maior lucro ao cofre público federal e além disso, segundo o artigo 154, inciso I da Constituição Federal de 1988, mediante lei complementar poderá instituir novos impostos não previstos na constituição, caso não sejam cumulativos e não tenham iguais fatos geradores dos demais impostos já previstos no rol do artigo 153 da mesma Carta Magna.

O autor James Marins do livro "Direito Processual Tributário Brasileiro Administrativo e Judicial", fala sobre o princípio da legalidade tributária como sendo necessário à 
segurança jurídica, e deste mesmo princípio ele salienta outros três princípios derivados:

No sistema constitucional tributário brasileiro, no entanto, assumem elevada expressão no contexto da justiça tributária os princípios da irretroatividade da lei tributária (art. 150, III, a, da CF/88) e da anterioridade (art. 150, III, b da CF/1988), bem como o princípio da noventena (art. 150, III, c, da CF/1988) (MARINS, 2019, p. 135).

Com isso, é possível verificar, que a aplicabilidade da lei deve observar os limites temporais (os prazos) para instituir um determinado tributo, a fim dos contribuintes se prepararem a um novo setor de arrecadação, podendo estes prazos ser de um ano (o exercício financeiro seguinte) ou noventa dias após instituído a nova lei. Na esfera federal, entre os impostos o IOF (Imposto sobre Operações Financeiras), II (Imposto de Importação) e o IE (Imposto de Exportação), dos quais são conhecidos como impostos extrafiscais, não estão submetidos ao princípio da anterioridade tributário e nem ao princípio da noventena, mas como todos os demais, devem observar os limites da lei.

O Código Tributário Nacional (Lei $n^{\circ} 5.172$, de 25 de Outubro de 1966) em seu artigo $3^{\circ}$, traz a definição de tributo como sendo uma prestação pecuniária exigível de maneira compulsória, não sendo portanto uma sanção aplicada pelo estado, sendo esta criada por meio de lei, da qual é exigida pela Administração Fazendária. $\mathrm{O}$ artigo $9^{\circ}$, inciso I do mesmo código afirma, que é vedado aos entes da federação, inclusive a União Federal, instituir ou majorar tributos sem a existência de lei anterior, exceto em casos previstos neste código. E por fim, o artigo 97 deste Código Tributário Nacional fala sobre as áreas de atuação das leis e até das convenções e tratados internacionais.

Em uma outra visão, a autora Josycler Aparecida Arana Santos em sua obra "A importância do Princípio da Estrita Legalidade para o Direito Tributário" afirma sobre os limites da atuação do estado, enquanto ente com poderes, dizendo que:

No caso específico em matéria tributária, o Princípio da Legalidade tem por função agir como o fiel da balança e evitar que o abuso dos poderes conferidos a este (o Estado) possam vir a torná-lo invencível por aquele 
(povo), garantindo a defesa contra atos obscuros e injustificados do poder Estatal (SANTOS, 1997, p. 332).

As leis trazem o que é chamado de "hipóteses tributárias", das quais são fatos em que uma vez praticados pelo contribuinte, geram a hipótese de incidência do tributo. Por exemplo, na lei $n^{\circ} 8.134 / 90$ traz as hipóteses em que poderá incidir o Imposto de Renda, devendo o administrador público fazendário arrecadar este tributo, obrigatoriamente, através de um ato administrativo vinculado, chamado de Lançamento Tributário. Os artigos 142 a 150 do Código Tributário Nacional apresentam os tipos de lançamento e como estes devem ser feitos pelo administrador, sob pena de nulidade do processo. A legalidade tributária também está presente ao definir sobre a obrigatoriedade do tributo, envolvendo a obrigação principal e a obrigação acessória. A obrigação principal envolve o devido pagamento do tributo e, por sua vez, a sua extinção, enquanto a obrigação acessória está ligada a declaração das informações necessárias ao fisco, para ocorrer o lançamento do crédito tributário, como assim esclarece a súmula 436 do Superior Tribunal de Justiça, da qual diz: "A entrega de declaração pelo contribuinte reconhecendo débito fiscal constitui o crédito tributário, dispensada qualquer outra providência por parte do fisco" (COMPACTO, 2019, p. 2017).

O Supremo Tribunal Federal no julgado RE 414.249 AgR, com relatoria do ministro Joaquim Barbosa, apresentou o princípio da legalidade como a expressão visível da vontade popular, como elemento fundamental da democracia, mas não impedindo a concessão de benefícios fiscais aos contribuintes, com base no artigo $150, \S 6^{\circ}$ da Constituição Federal de 1988. Parte desta decisão assim fala:

Cabe ao Poder Legislativo autorizar a realização de despesas e a instituição de tributos, como expressão da vontade popular. Ainda que a autorização orçamentária para arrecadação de tributos não mais tenha vigência ("princípio da anualidade"), a regra da legalidade tributária estrita não admite tributação sem representação democrática. Por outro lado, a regra da legalidade é extensível à concessão de benefícios fiscais, nos termos do art. $150, \S 6^{\circ}$, da Constituição. Trata-se de salvaguarda à atividade legislativa, que poderia ser frustrada na hipótese de assunto de grande relevância ser tratado em texto de estatura ostensivamente menos relevante [...] (BARBOSA, 2019, p. 69). 
Sob esta mesma linha de raciocínio, Luís Eduardo Schoueri em sua obra "Direito Tributário" apresenta a seguinte argumentação:

Em matéria tributária, o Princípio da Legalidade é anterior mesmo ao Estado de Direito. É o direito de concordar com a tributação e controlar o modo como os recursos arrecadados são empregados. Mesmo em regimes ditatoriais, a matéria tributária foi excepcionada, preservandose o princípio de que a cobrança de um tributo é condicionada à concordância prévia dos contribuintes, diretamente ou por meio de seus representantes (SCHOUERI, 2018, p. 292).

A legalidade tributária abrange não somente a obrigação principal de pagar o tributo, como também a obrigação acessória, da qual envolve a parte da documentação, da contabilização desta contribuição, sendo esta obrigação muitas das vezes o ônus do contribuinte, mas não pode o Fisco cobrar uma obrigação acessória mais do que for previamente estabelecido pela lei, protegendo assim o contribuinte de sofrer além do devido, como assim se interpreta os artigos 111, inciso III e artigo 113 do Código Tributário Nacional Brasileiro.

\section{a. A Legalidade Tributária nos processos administrativo e judicial e sua relação aos Impostos Federais:}

No âmbito da Administração Pública Federal, a União Federal é a pessoa jurídica de Direito Público responsável pela legislação e arrecadação dos Impostos Federais, dos quais estão dispostos no artigo 153 da Constituição Federal de 1988, sendo esta (União Federal) o ente que mais arrecada impostos, exercendo esta função por meio de seu órgão fiscal, a Receita Federal do Brasil segundo a Lei Federal n 11.457/07. Entre estes impostos estão o Imposto de Renda sobre pessoas física e jurídica, imposto sobre Produtos Industrializados, Imposto de Propriedade Territorial Rural e entre outros.

O processo administrativo fiscal federal é disciplinado pelo Decreto $n^{\circ} 70.235 / 72$, do qual apresenta dispositivos sobre a cobrança destes impostos federais. O princípio da legalidade tributária é nitidamente perceptível deste Decreto, como o artigo 10, inciso IV do qual trata sobre o auto de infração, que terá a disposição legal infringida pelo contribuinte, para que este fique ciente da infração da qual está sendo acusado. $O$ 
princípio do contraditório e ampla defesa no processo administrativo tem como base primária no artigo $5^{\circ}$, inciso LV da Constituição Federal de 1988, pois uma vez não observado, pode levar não somente a ilegalidade, como também a nulidade do processo. Bem como, uma vez realizado o lançamento tributário pela autoridade fazendária, deverá esta notificar o contribuinte, alegando a disposição legal referente ao crédito tributário cobrado, segundo o artigo 11 do decreto supracitado.

Também no âmbito do processo administrativo fiscal federal, a Lei $n^{\circ}$ 9.784/99 também enfatiza a presença do princípio da legalidade tributária, sendo esse o princípio que rege os atos da administração fazendária, segundo o artigo $2^{\circ}$ desta lei, do qual uma vez não observados, pode levar a nulidade do ato administrativo, segundo o artigo 53 desta lei supra mencionada. Deve-se observar os prazos de preclusão e decadência, ambos de 5 (cinco) anos, dos quais o Administrador Público Federal deve cuidar, a fim de poder lançar o tributo e cobra-lo sem infringir estes limites temporais da lei e se caso, tanto o prazo de um ou de outro não for cumprido, extingue o crédito tributário, como assim fala o artigo 153, inciso $V$ do Código Tributário Nacional. A autora Denise Lucena Cavalcante em sua obra "Execução Fiscal Administrativa e Devido Processo Legal" afirma, que:

O fato de o fisco continuar na tarefa de cobrança administrativa do crédito tributário não significa, de modo algum, que se esteja violando princípios constitucionais, ou agredindo o devido processo legal administrativo ou judicial.

A violação das garantias constitucionais não decorre desta alteração do procedimento da cobrança, mas, sim, se isto for feito de forma arbitrária e sem observância do devido processo legal (CAVALCANTE, 2007, p. 50).

Portanto, os princípios fundamentais regem o andamento do processo administrativo, inclusive o princípio da legalidade, trazendo assim maior segurança jurídica dentro da relação entre o contribuinte e o estado, proporcionando o devido andamento da demanda. No âmbito judicial, em especial na justiça federal, a tutela jurisdicional já garante ao contribuinte poder acessa-la sem restrição, como fundamenta o artigo $5^{\circ}$, inciso XXXV da Constituição Federal de 1988, sendo que a matéria envolvendo a União Federal, então a competência pertence a esta esfera da justiça federal, como 
dispõe o artigo 109, inciso I desta mesma Constituição Federal. Assim sendo, o processo judicial é regido pelo Código de Processo Civil de 2015 e pela lei federal $n^{\circ}$ $6.830 / 80$, da qual esta fala sobre a cobrança judicial de dívida ativa da Fazenda Pública. Uma vez constituído o crédito tributário, o Fisco tem prazo para, caso deseje, cobrá-lo por meio judicial, através da execução fiscal, pois caso contrário, o direito poderá sofrer uma preclusão.

O fisco também deverá observar o princípio da legalidade dentro do processo judicial, a fim de comprovar a legitimidade da cobrança do crédito tributário, devendo apresentar as provas materiais da constituição deste crédito, a fim de ser apreciado o mérito e assim, para que o contribuinte possa exercer seu direito de defesa. Sobre a justiça tributária, James Marins em sua obra "Direito Processual Tributário: administrativo e judicial" apresenta um importante ponto sobre sua definição, ao dizer:

Este ponto de vista sobre a justiça em sua relação com o Direito Tributário precisa ser melhor compreendido à luz da Constituição Federal de 1988 que não se limita aos princípios de 'microjustiça' tributária, que é aquela que se ocupa tão somente com a justiça em sua afetação do contribuinte individualmente considerado (MARINS, 2019, p. 136).

Dentro do contexto do processo judicial tributário, o princípio da legalidade torna- se uma grande fundamentação para as peças tributárias, como no caso da Ação Anulatória, da qual com base no artigo 319 do Código de Processo Civil de 2015 e no artigo 38 da lei $n^{\circ} 6.830 / 80$, pois esta é proposta, quando deseja contestar alguma ilegalidade da cobrança tributária praticada pelo fisco, podendo ser uma ilegalidade no ato do lançamento tributário, por exemplo, pedindo assim para que o Juiz aprecie o mérito, anulando o crédito cobrado indevidamente, com base no artigo 156, inciso $X$ do Código Tributário Nacional. Entretanto, caso a decisão de primeira instância não reconheça a ilegalidade tributária, é possível o contribuinte recorrer da decisão em segunda instância, por exemplo, por meio de uma Apelação, com base nos artigos 1.009 a 1.014 do $\mathrm{CPC} / 15$. E na esfera constitucional, se houver alguma ofensa ao princípio da legalidade tributária, poderá ser proposto um Recurso Extraordinário ao Supremo Tribunal Federal, com base no artigo 102, $3^{\circ}$ da Constituição Federal de 1988. E assim, para ressaltar a importância desta temática perante a suprema corte 
brasileira, o Recurso Extraordinário $n^{\circ}$ 704.292, julgado pelo Ministro Dias Toffoli assim dispõe:

É inconstitucional, por ofensa ao princípio da legalidade tributária, lei que delega aos conselhos de fiscalização de profissões regulamentadas a competência de fixar ou majorar, sem parâmetro legal, o valor das contribuições de interesse das categorias profissionais e econômicas, usualmente cobradas sob o título de anuidades, vedada, ademais, a atualização desse valor pelos conselhos em percentual superior aos índices legalmente previstos (TOFFOLI, 2019, Tema 540, p. 3).

Por fim, a legalidade tributária também influencia na questão da competência da justiça, ao analisar o mérito da causa, pois em regra geral, quando no processo envolver a União Federal, seja no polo ativo ou no polo passivo, então a competência será federal, mas no caso de um processo de execução fiscal, não tenha justiça federal no domicílio da parte executada, então a competência será da justiça estadual, tornando-se como sendo uma justiça residual neste caso, segundo o entendimento do artigo 109, $3^{\circ}$ e $\S^{\circ}$ da Constituição Federal de 1988.

\section{b. Os Impostos Federais sob a ótica da legalidade tributária:}

O rol de impostos federais disposto pelo artigo 153 da Constituição Federal de 1988 é considerado um rol taxativo, ou seja, limitando-se somente a aqueles previstos na Constituição Federal, o que limita a cobrança tributária da União Federal, não podendo esta criar impostos federais, sem a devida permissão de lei. As espécies de impostos federais são o Imposto de Importação, Imposto de Exportação, Imposto de Renda, imposto sobre Produtos Industrializados, imposto sobre Operações Financeiras, Imposto Territorial Rural e Imposto sobre Grandes Fortunas (mediante aprovação de lei complementar prévia). Somente estes poderão ser cobrados pela União, estabelecendo uma prévia relação jurídica entre o Fisco Federal e os Contribuintes. E - Código Tributário Nacional disciplina de maneira geral, sobre estes impostos federais, como se, por exemplo, vê entre os artigos 19 a 22 (Imposto sobre a Importação), artigos 23 a 28 (Imposto sobre a Exportação), artigos 29 a 31 (Imposto Territorial Rural) e entre outros. 
Não somente com relação as obrigações principais (pagamento), mas também com relação as obrigações acessórias, devem estar de acordo com as exigências legais, como por exemplo a apresentação da escrituração contábil completa e de demais documentos no caso da declaração do Imposto de Renda, como é regulamentado pelo Decreto $n^{\circ}$ 9.580/2018. Com isso, um princípio intimamente ligado ao princípio da legalidade tributária, seria o princípio da "não surpresa", ou seja, torna-se previsível ao contribuinte devedor do tributo o que ele deve fazer, como deve proceder diante de um imposto, bem como, o fisco deve não causar uma "surpresa" ao contribuinte. Sobre isso, Leandro Plausen em sua tese "Segurança Jurídica, Certeza do Direito e Tributação" apresenta seu entendimento sobre este assunto, ao falar:

Mais do que previsibilidade e do que não-surpresa, pois, cuida-se de assegurar ao contribuinte o conhecimento antecipado daquilo que, sendo decorrente publicada, Ihe será com certeza imposto, incidindo sobre os atos que então venham a ser praticados ou sobre os fatos ou situações que se verifiquem em conformidade com a previsão legal [...] (PAULSEN, 2005, p. 128).

Um importante destaque é importante ser feito, com relação aos impostos extrafiscais, pois estes estão ligados a dinâmica da atividade econômica, da qual possui suas mudanças no âmbito nacional ou internacional, e com isso, impostos federais como o Imposto de Importação, Imposto sobre Produtos Industrializados e o Imposto sobre operações de crédito, câmbio e seguro, ou relativas a títulos ou valores mobiliários (IOF). Nestes casos, estes não se submetem aos princípios da anterioridade tributário e nem ao princípio da noventena, segundo o artigo $150, \S 1^{\circ}$ da Constituição Federal de 1988, permitindo ao Poder Executivo maior flexibilidade em aumentar ou diminuir suas alíquotas, a fim de serem compatíveis com a realidade econômica, mas sempre observando os limites previstos em lei federal. Com a preocupação do legislador constituinte quanto a realidade econômica, inclusive favorecendo o microempreendedor (artigo 150, IX da Constituição Federal de 1988), o Supremo Tribunal Federal na Ação Direta de Inconstitucionalidade (ADIn n 1643) entendeu não haver inconstitucionalidade na lei, quando traz tratamento favorável as microempresas e empresas de pequeno porte, ao dizer: 
AÇÃO DIRETA DE INCONSTITUCIONALIDADE. SISTEMA INTEGRADO DE PAGAMENTO DE IMPOSTOS E CONTRIBUIÇÕES DAS MICROEMPRESAS E EMPRESAS DE PEQUENO PORTE. CONFEDERAÇÃO NACIONAL DAS PROFISSÕES LIBERAIS. PERTINÊNCIA TEMÁTICA. LEGITIMIDADE ATIVA. PESSOAS JURÍDICAS IMPEDIDAS DE OPTAR PELO REGIME. CONSTITUCIONALIDADE. Por disposição constitucional (CF, artigo 179), as microempresas e empresas de pequeno porte devem ser beneficiadas, nos termos da lei, pela 'simplificação de suas obrigações administrativas, tributárias, previdenciárias e creditícias, ou pela eliminação ou redução destas' (CF, artigo 179). (CORRÊA, 2019, p. 32).

Sendo assim, é perceptível que a legalidade tributária intervém na realidade econômica, possibilitando ou não a cobrança de um determinado valor, podendo a alíquota aplicada aumentar ou diminuir de acordo com as possibilidades legais. A alíquota aplicada tem influência no valor de um imposto, podendo ser, como dito antes, alterado pelo poder executivo, através de um decreto, mas o que não poderá ser alterado é o fato gerador, a base de cálculo, da qual é instituída por ato do poder legislativo, ou seja, pela própria lei, podendo ser um rendimento, um valor específico, a depender do que o legislador entender como tributável, mas sempre considerando os casos de imunidades previstos no artigo 150, VI da Constituição Federal de 1988.

Ainda nessa mesma linha de raciocínio, o Supremo Tribunal Federal ao analisar os casos envolvendo o Imposto de Importação e o Imposto de Exportação, dos quais estão ligados ao comércio exterior, o Recurso Extraordinário 225.602 diz que deve haver expressa determinação do texto Constitucional, para a criação de uma lei complementar, com o fim de disciplinar a matéria do Imposto de Importação. Ou seja, se o texto constitucional não fez expressa exigência da criação de uma lei complementar, então entende-se não ser necessária para isso. Assim também foi o entendimento apresentado pelo Agravo Regimental no Recurso Extraordinário $\mathrm{n}^{\circ}$ 219.874, enfatizando a necessidade da interpretação restrita ao texto da constituição, limitando assim a atuação do fisco federal.

Os atos de lançamento tributário federal são atos administrativos por excelência, sendo atos vinculados, ou seja, não cabendo ao administrador público fazer um juízo de valores, avaliando a conveniência e oportunidade, mas sim deverá aplicar as 
exigências restritas da lei tributária, a fim de constituir este crédito tributário. No caso dos impostos federais de importação e exportação, estes são submetidos obrigatoriamente pela lei, pelo lançamento por declaração, com base no artigo 147 do Código Tributário Nacional. E no caso do Imposto de Renda, do Imposto sobre produtos Industrializados e do Imposto sobre Operações Financeiras, o lançamento a estes submetidos pela lei é o lançamento por homologação, previsto no artigo 150, $\S 4^{\circ}$ deste Código Tributário Nacional.

É possível perceber que a legalidade tributária rege as relações jurídicas entre a União Federal, enquanto fisco, e os contribuintes, sujeitos passivos, cabendo ao ente tributante a fiscalização do cumprimento destes deveres legais, devendo fazer a fiscalização das declarações feitas, analisando os documentos apresentados, a fim de verificar a sua veracidade e assim poder se chegar ao valor do tributo devido, tratando-se de exigência com base no artigo 196 do Código Tributário Nacional. Assim é o entendimento apresentado pelo autor Luciano Amaro em sua obra "Direito Tributário Nacional", ao dizer: "Para esses efeitos, o procedimento de fiscalização há de ser informado ao sujeito passivo, de preferência - diz o parágrafo único do art. 196 - mediante termo lavrado em livro fiscal que seja exibido [...]" (AMARO, 2017, p. 514).

Por fim, o artigo 37, caput da Constituição Federal de 1988 rege a Administração Pública, sendo que um dos princípios que as rege é o princípio da legalidade, reconhecendo uma hierarquia superiora da lei, em relação aos atos administrativos, dos quais são presumidamente, uma vez praticados, portadores desta legalidade. A análise do mérito do ato administrativo fiscal, como uma isenção fiscal, não cabe ser questionado, apenas se houver uma evidente ilegalidade, o que assim, como dito anteriormente, caberá a apreciação da Tutela Jurisdicional.

\section{CONSIDERAÇÕES FINAIS}

Ao longo do desenvolvimento da temática sobre o princípio da legalidade tributária no âmbito processual e seu impacto aos Impostos Federais brasileiros, é possível notar a importância de seu estudo, pois mesmo este assunto sendo de grande conhecimento dos juristas, ele possui uma grande vastidão, da qual sempre é 
acompanhada com a evolução e as mudanças da Lei, da jurisprudência e até mesmo da atuação do fisco federal. A União Federal é a pessoa jurídica de Direito Público, da qual possui o maior número de arrecadações previstas no texto constitucional (art. 153), e com isso, surge a necessidade da observância da lei, a fim de limitar a atuação do poder estatal federal e delimitar seus alcances sobre os fatos gerados. A não observância do princípio da legalidade tributária, do qual também tem sua base no artigo 37, caput da Constituição Federal poderá tornar nulo o ato administrativo fazendário (lançamento tributário), podendo o poder judiciário declará-lo de ofício, com base na defesa do contribuinte, em face dos atos da Fazenda Pública.

Não somente no direito material, mas principalmente na esfera processual, seja ela judicial ou administrativa, a observância do princípio da legalidade tributária torna-se uma tarefa grave, necessitando de atenção. O poder administrativo poderá anular seus atos de ofício, caso observada alguma ilegalidade, mas o que na prática mais se percebe, é o contribuinte destes impostos federais se socorrer na esfera federal, a fim de resolver a lide e conseguir o deferimento prévio de sua defesa. O Supremo Tribunal Federal, segundo o artigo 102, inciso I, alínea "a” desta Constituição Federal de 1988, tem a possibilidade de declarar a inconstitucionalidade até mesmo de uma lei ou a instituição de um novo imposto, que não tenha prévia autorização constitucional, pois mesmo a União Federal tendo a competência residual de instituir novos impostos federais, esta não pode descuidar os limites impostos a ela, pois trata-se de um estado Democrático de Direito, como assim prevê o artigo $1^{\circ}$, caput da Constituição e como assim impacta na lógica do Código Tributário Nacional, segundo o artigo $3^{\circ}$ deste código.

Conclui-se que, a aplicabilidade tributária nacional sempre é regida pelo princípio da legalidade, do qual influencia nos prazos de cobrança tributária, na execução fiscal, na instituição de novos tributos e até nos limites de sua base de cálculo, o que gera grandes impactos ao mundo econômico brasileiro, gerando assim grande atenção não somente aos doutrinadores do Direito, como a outras áreas do conhecimento, sendo válido o estudo posteriormente de maneira multidisciplinar, entendo assim sua relevância prática. 


\section{REFERÊNCIAS}

AMARO, Luciano. Direito tributário brasileiro. 22. ed. São Paulo: Editora Saraiva, 2017.

BARBOSA, Min. Joaquim. RE 414.249 AgR. j. 31-8-2010, 2ª̣T, DJE de 16-11-2010. Disponível

em: <http://www.stf.jus.br/portal/constituicao/artigo.asp?item=1421\&tipo=CJ\&termo=37> Acesso em: 18 de Novembro de 2019.

BRASIL. Constituição da República Federativa do Brasil de 1988. Diário Oficial da União, Brasília, DF, de 05 de Out. de 1988. Disponível em: <http://www.planalto.gov.br/ccivil_03/constituicao/constituicao.htm> Acesso em: 29 de Outubro de 2019.

BRASIL. Decreto n 9.580, de 22 de Novembro de 2018. Regulamenta a tributação, a fiscalização, a arrecadação e a administração do Imposto sobre a Renda e Proventos de Qualquer Natureza. Diário Oficial da União, Brasília, DF, de 23 de Nov. de 2018. Disponível em: <http://www.planalto.gov.br/ccivil_03/_ato20152018/2018/decreto/D9580.htm> Acesso em: 30 de Outubro de 2019.

BRASIL. Decreto $n^{\circ}$ 70.235, de 6 de Março de 1972. Dispõe sobre o processo administrativo fiscal, e dá outras providências. Diário Oficial da União, Brasília, DF, de 07 de Mar. de $1972 . \quad$ Disponível em: <http://www.planalto.gov.br/ccivil_03/decreto/D70235cons.htm> Acesso em: 29 de Outubro de 2019.

BRASIL. Lei $\mathbf{n}^{\circ}$ 5.172, de 25 de Outubro de 1966. Dispõe sobre o Sistema Tributário Nacional e institui normas gerais de direito tributário aplicáveis à União, Estados e Municípios. Diário Oficial da União, Brasília, DF, de 27 de Out. de 1966. Disponível em: <http://www.planalto.gov.br/ccivil_03/leis//5172.htm> Acesso em: 29 de Outubro de 2019. 
BRASIL. Lei $n^{\circ}$ 6.830, de 22 de Setembro de 1980. Dispõe sobre a cobrança judicial da Dívida Ativa da Fazenda Pública, e dá outras providências. Diário Oficial da União, Brasília, DF, 24 de Set. de 1980. Disponível em:<http://www.planalto.gov.br/ccivil_03/leis/l6830.htm> Acesso em: 30 de Outubro de 2019.

BRASIL. Lei $\mathbf{n}^{\circ}$ 8.134, de 27 de Dezembro de 1990. Altera a legislação do Imposto de Renda e dá outras providências. Diário Oficial da União, Brasília, DF, de 28 de Dez. de 1990. Disponível em: < http://www.planalto.gov.br/ccivil_03/leis/L8134.htm> Acesso em: 29 de Outubro de 2019.

BRASIL. Lei $\mathbf{n}^{\circ}$ 9.784, de 29 de Janeiro de 1999. Regula o processo administrativo no âmbito da Administração Pública Federal. Diário Oficial da União, Brasília, DF, de 01 de Fev. de 1999. Disponível em: < http://www.planalto.gov.br/ccivil_03/leis/19784.htm> Acesso em: 29 de Outubro de 2019.

BRASIL. Lei $n^{\circ}$ 11.457, de 16 de Março de 2007. Dispõe sobre a Administração Tributária Federal. Diário Oficial da União, Brasília, DF, de 19 de Mar. de 2007. Disponível em: <http://www.planalto.gov.br/ccivil_03/_Ato20072010/2007/Lei/L11457.htm> Acesso em: 30 de Outubro de 2019.

CAVAlCANTE, Denise Lucena. Execução Fiscal Administrativa e devido Processo Legal. Universidade Federal do Ceará: 2007.

COMPACTO, Vade Mecum Saraiva . Obra coletiva de autoria da Editora Saraiva com a colaboração de Livia Céspedes e Fabiana Dias da Rocha. 21. ed. São Paulo: Editora Saraiva Educação, 2019.

CORRÊA, Ministro Maurício. ADI 1.643-1 UF. j. 05-12-2002, DJE 14-03-2003. Tribunal Pleno.

$<$ https://stf.jusbrasil.com.br/jurisprudencia/14745753/acao-direta-deinconstitucionalidade-adi-1643-uf?ref=juris-tabs> Acesso em: 18 de Novembro de 2019. 
MARINS, James. Direito Processual Tributário Brasileiro: administrativo e judicial. 12. ed. São Paulo: Editora Thomson Reuters Brasil, 2019.

PAULSEN, Leandro. Segurança Jurídica, Certeza do Direito e Tributação: A concretização da certeza quanto à instituição de tributos através das garantias da legalidade, da irretroatividade e da anterioridade. Porto Alegre: Universidade Federal do Rio Grande do Sul, 2005.

RIBEIRO, Ricardo Lodi. Legalidade Tributária, Tipicidade Aberta. Conceitos Indeterminados e Cláusulas Gerais Tributárias. Edição v. 229. Rio de Janeiro: Editora Fundação Getúlio Vargas, publicado em 01 de Julho de 2002, Seção Doutrina, Número de Série DOI (https://doi.org/10.12660/rda.v229.2002.46446), Revista de Direito Administrativo.

Disponível

em: $<$ http://bibliotecadigital.fgv.br/ojs/index.php/rda/article/view/46446> Acesso em: 18 de Novembro de 2019.

SANTOS, Josycler Aparecida Arana. A importância do princípio da estrita legalidade para o Direito Tributário. Londrina: Universidade Estadual de Londrina, 1997.

SCHOUERI, Luís Eduardo. Direito Tributário. 8. ed. São Paulo: Editora Saraiva Educação, 2018.

TOFFOLI, Min. Dias. RE 704.292. j. 19-10-2016, DJE de 3-8-2017, Tema 540. Disponível em: < file://C:/Users/User/Downloads/texto_312323728.pdf> Acesso em: 18 de Novembro de 2019.

Enviado: Dezembro, 2020.

Aprovado: Dezembro, 2020. 